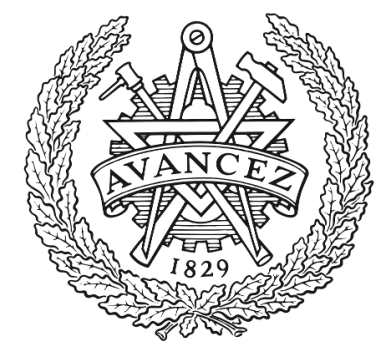

CHALMERS

UNIVERSITY OF TECHNOLOGY

\title{
Directional dual-band slotted semi-circular inverted-F antenna for WLAN applications
}

Downloaded from: https://research.chalmers.se, 2023-04-26 09:55 UTC

Citation for the original published paper (version of record):

Chen, W., Yin, J., Li, M. et al (2015). Directional dual-band slotted semi-circular inverted-F antenna for WLAN applications. Electronics Letters, 51(24): 1960-1961.

http://dx.doi.org/10.1049/el.2015.2413

N.B. When citing this work, cite the original published paper. 


\section{A Directional Dual-band Slotted Semi- Circular Inverted-F Antenna For WLAN Applications}

Wei Chen, Jungang Yin, Meiju Li, Fuhai Li and Jian Yang

\begin{abstract}
A simple and compact directional dual-band semi-circular inverted-F antenna for WLAN applications is reported. Two pairs of semi-circular slots as well as a pair of arms are employed to generate the dual resonances in the 2.4-2.48 and 5.2-5.8 GHz bands. The measured results show that the proposed antenna can provide two 10dB impedance bandwidths of $160 \mathrm{MHz}(2.40-2.56 \mathrm{GHz})$ and $900 \mathrm{MHz}(4.95-5.85$ $\mathrm{GHz}$ ), respectively. Nearly constant directivities (about $4.7 \mathrm{dBi}$ ) are observed in the lower band, while directivities in the upper band vary between 6.3 and $8.6 \mathrm{dBi}$
\end{abstract}

Introduction: Multiband antennas have increasingly attracted great attention as indoor wireless technologies develop rapidly, such as the smart home system based on wireless sensor networks technology. A large number of antennas have been designed for wireless local area network (WLAN) applications [1]-[3], most of which have omnidirectional radiation patterns as applied to various wireless terminals. However, it is in some cases required that the antenna is directional to allow the installation against a wall or on a ceiling surface, particularly for indoor wireless access points or point-to-point communications [4]-[5]. Slotted structures are often utilized in the multi-band antennas [6]-[7]; as for dual-band patches in [8]-[9], the first resonance is due to the fundamental mode of the main patch, while the second is due to the currents flowing along the slot edges.

In this article, we present a new directional dual-band slotted semicircular inverted-F antenna, which is compact, low-cost and capable of covering the $2.4-2.48 / 5.2-5.8 \mathrm{GHz}$ WLAN bands. It is designed for a smart wireless gateway in a WLAN-based smart home system.

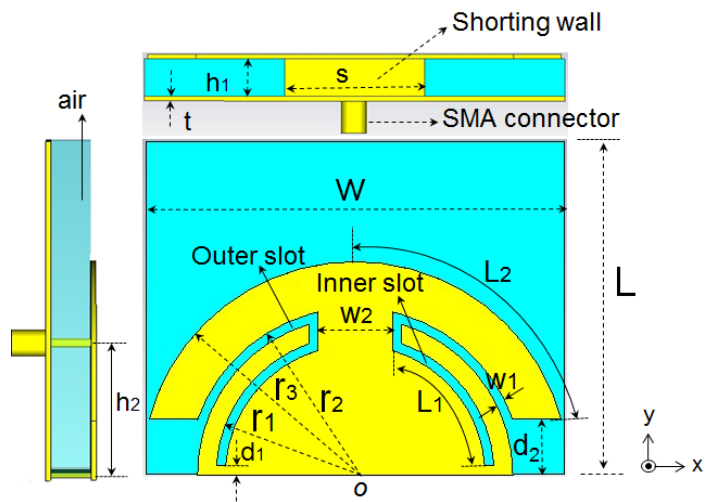

Fig. 1 Geometry of the proposed antenna (yz-plane is the E-plane while $x z$-plane is the H-plane)

Table I Geometric parameters for the proposed antenna

\begin{tabular}{c|c|c|c}
\hline \hline parameter & value & parameter & value \\
\hline$S$ & $21.0 \mathrm{~mm}$ & $t$ & $0.1 \mathrm{~mm}$ \\
\hline$L$ & $41.4 \mathrm{~mm}$ & $d_{1}$ & $1.2 \mathrm{~mm}$ \\
\hline$w$ & $51.8 \mathrm{~mm}$ & $d_{2}$ & $7.0 \mathrm{~mm}$ \\
\hline$r_{1}$ & $17.3 \mathrm{~mm}$ & $w_{1}$ & $1.2 \mathrm{~mm}$ \\
\hline$r_{2}$ & $20.7 \mathrm{~mm}$ & $w_{2}$ & $9.2 \mathrm{~mm}$ \\
\hline$r_{3}$ & $26.5 \mathrm{~mm}$ & $h_{1}$ & $4.6 \mathrm{~mm}$ \\
\hline$h_{2}$ & $20.0 \mathrm{~mm}$ & & \\
\hline \hline
\end{tabular}

Antenna structure: Fig. 1 and Table I show the geometry of the proposed dual-band slotted semi-circular inverted-F antenna. As can be seen, its total size is $41.4 \times 51.75 \times 4.6 \mathrm{~mm}^{3}$, which is much thinner than that $\left(43 \times 26 \times 12 \mathrm{~mm}^{3}\right)$ of a $2.4 / 5.8 \mathrm{GHz}$ dual-band directional antenna proposed in [4] for RFID reader applications, and much more compact than that $\left(57 \times 57 \times 21 \mathrm{~mm}^{3}\right)$ of a $2.5-4.8 \mathrm{GHz}$ slot antenna designed for WLAN systems in [5].
Results and discussion: The proposed antenna is simulated and optimized by using CST MWS. The surface current distribution shown in Fig. 2 implies that dual-band performance can be obtained by tuning the length of the inner semi-circular slots $\left(L_{1}\right)$ and the outer semicircular arms $\left(L_{2}\right)$.

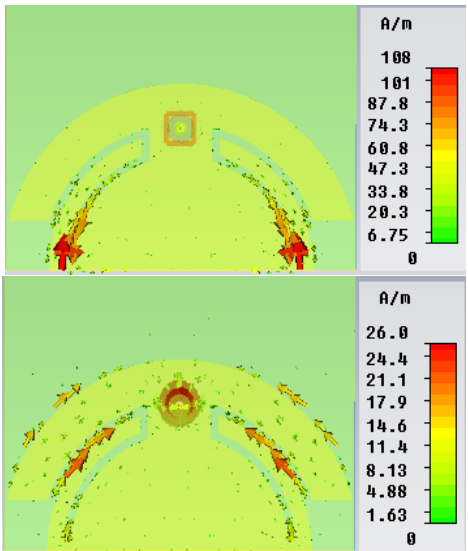

Fig. 2 Surface currents at lower (top) and upper (bottom) band
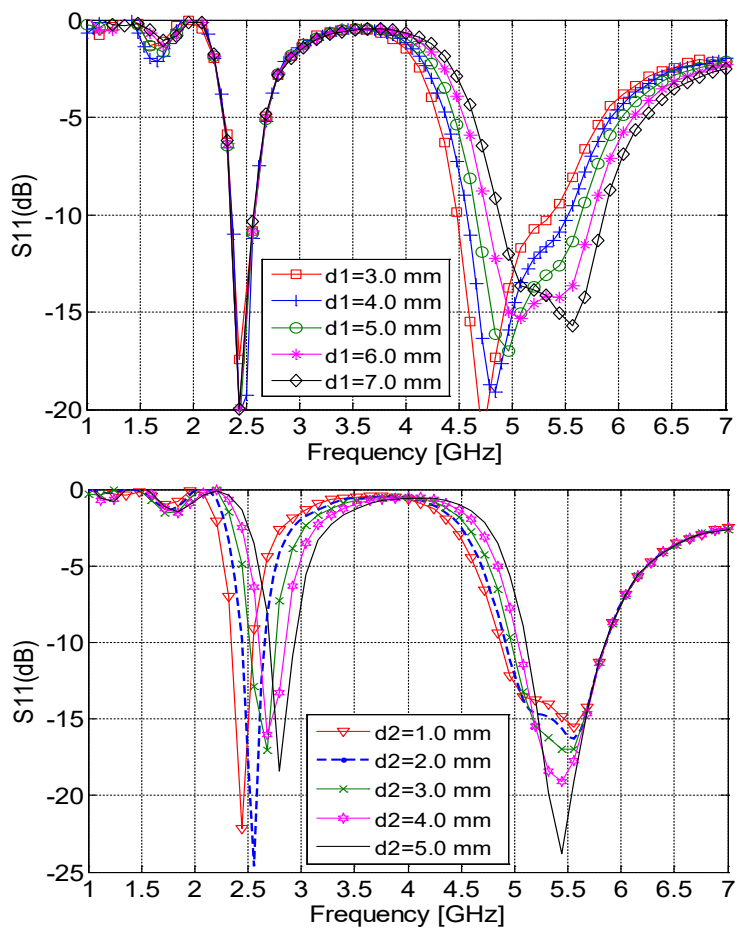

Fig. 3 Single parameter $d_{1}$ (top) and $d_{2}$ (bottom) sweeping for $S_{11}$

Parametric sweeps have been performed, where one parameter is swept at one time while the others are fixed. The critical lengths $L_{1}$ and $L_{2}$ are primarily associated with $d_{1}$ and $d_{2}$, respectively, and the results of $d_{2}$ and $d_{1}$ sweeps are exhibited in Fig. 3. The outer slots can provide so-called isolation between the semi-circular arms and the inner slots. When the length of the inner slots is changed, the length of the outer semi-circular arms remains unchanged, and vice versa. As indicated from Fig. $3, d_{1}$ and $d_{2}$ could be used to fine-tune the dual resonance dips in a nearly separate way.
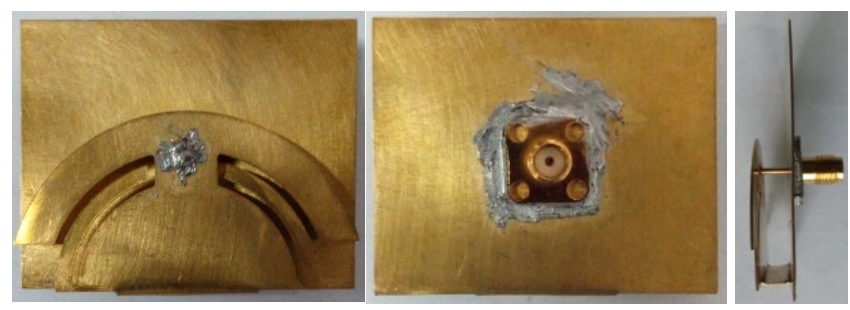
Fig.4 Top/bottom/side view of the fabricated antenna prototype.

As can be seen in Fig. 4, the fabricated trapezoidal inverted-F antenna is made of copper and probe-fed through an air cavity by an SMA connector.

Fig. 5 shows the measured and simulated return loss of the proposed antenna. Good agreement between simulation and measurement results is achieved. The measured $10 \mathrm{~dB}$ impedance bandwidth in the dual-band are $160 \mathrm{MHz}(2.40-2.56 \mathrm{GHz})$ and $900 \mathrm{MHz}(4.95-5.85 \mathrm{GHz})$; the antenna can thus fully cover the dual WLAN bands.

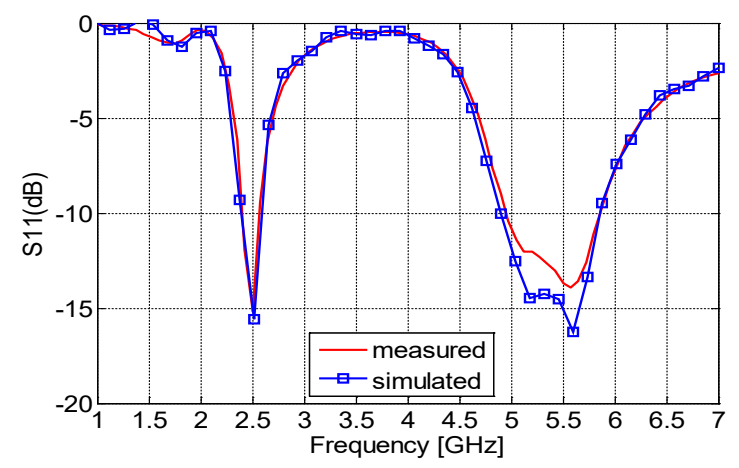

Fig. 5 Simulated and measured $S_{11}$ of the proposed antenna
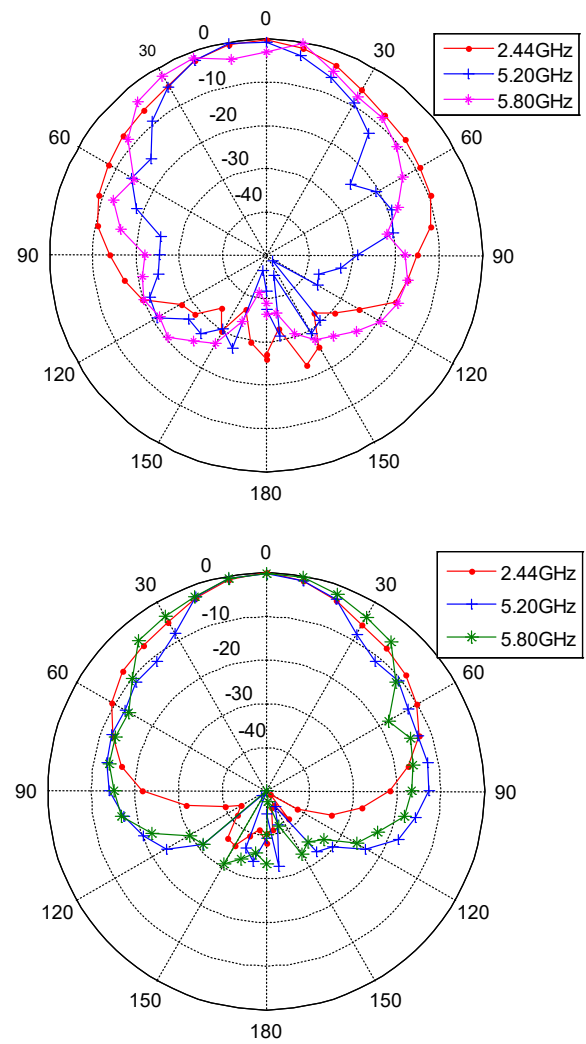

Fig. 6 Measured co-polar patterns in E-plane (top) and H-plane (bottom) at different frequencies

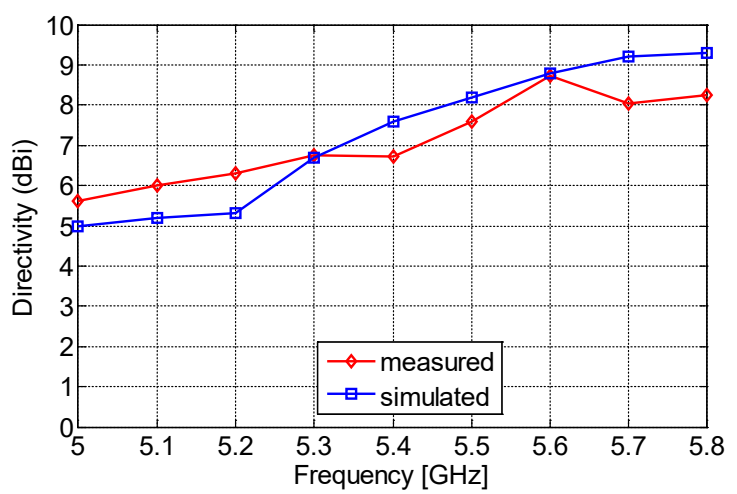

Fig. 7 Measured directivity spectrum in the upper band
The measured co-polar patterns in the E- and H-planes are displayed in Fig. 6. It can be seen clearly that the proposed antenna has good directional radiation patterns for all frequencies. The measured directivity is $4.7 \mathrm{dBi}$ at $2.44 \mathrm{GHz}$. The measured and simulated directivity spectrums are compared in Fig.7. It can be observed that the measured directivities vary from 6.3 to $8.6 \mathrm{dBi}$ at the upper band.

Conclusion: A new directional dual-band slotted semi-circular inverted$\mathrm{F}$ antenna has been proposed and investigated in this article. The measurement results of the prototype agree quite well with the simulation results. According to the measurement results, about $160 \mathrm{MHz}$ and $900 \mathrm{MHz}$ bandwidths defined by a return loss better than $10 \mathrm{~dB}$ are observed at the lower and upper WLAN bands, respectively; the directivities are about $4.7 \mathrm{dBi}$ at the lower band $(2.4-2.48 \mathrm{GHz})$ while vary from 6.3 to $8.6 \mathrm{dBi}$ at the upper band $(5.2-5.8 \mathrm{GHz})$. Besides, the proposed antenna is compact, low cost and easy to fabricate, making it ready to be applied in a WLAN-based smart home system.

Acknowledgments: The authors would like to thank all the support from the Youth Researcher Growth Program at Hunan University in China and the collaboration with the antenna group at Chalmers University of Technology in Sweden.

Wei Chen, Jungang Yin, Meiju Li and Fuhai Li (Dept.of Electronics, Hunan University, Changsha, 410082, China)

E-mail: jg_yin@hnu.edu.cn

Jian Yang (Dept. of Signals and Systems, Chalmers University of Technology, Gothenburg 412-96, Sweden)

\section{References}

1. Y.-L. Kuo and K.-L. Wong, "Printed double-T monopole antenna for 2.4/5.2 GHz dual-band WLAN operations," IEEE Trans. Antennas Propag., vol. 51, no. 9, pp. 2187-2192, Sep. 2003.

2. K.-L. Wong, L.-C. Chou and C.-M. Su, "Dual-band flat-plate antenna with a shorted parasitic element for laptop applications," IEEE Trans. Antennas Propag., vol. 53, no. 1, pp. 539-544, Jan. 2005.

3. H. Zhang and H. Xin, "A dual-band dipole antenna with integrated balun," IEEE Trans. Antennas Propag., vol. 57, no. 3, pp. 786-789, Mar. 2009.

4. XuLin Quan, RongLin Li, YueHui Cui and Manos M Tentzeris, "Analysis and design of a compact dual-band directional antenna," IEEE Antennas Wireless Propag. Lett., vol. 11, pp. 547-550, 2012.

5. C. R. Medeiros, E. B. Lima, J. R. Costa and C. A. Fernandes, "Wideband slot antenna for WLAN access points," IEEE Antennas Wireless Propag. Lett., vol. 9, pp. 79-82, 2010.

6. C.-Y. Huang and E.-Z. Yu, "A slot-monopole antenna for dual-band WLAN applications," IEEE Antennas Wireless Propag. Lett., vol.. 10, pp. 500-502, 2011.

7. N. Zhang, P. Li, B. Liu, X. W. Shi and Y. J. Wang, "Dual-band and low cross-polarisation printed dipole antenna with L-slot and tapered structure for WLAN applications", Electron. Lett., no. 47, pp. 360-361, 2011.

8. Jeen-Sheen Row, "Dual-frequency Triangular Planar Inverted-F antenna," IEEE Trans. Antennas Propag., vol. 53, no. 2, pp. 874-876, 2005.

9. T. Huynhand K. F. Lee, "Single-layer single-patch wideband microstrip antenna," Electron. Lett., vol. 31, pp. 1310-1312, Aug. 1995. 